\title{
The pain in the Emergency Department: Choosing and treating wisely before and during the COVID-19 era
}

\author{
Erika Poggiali, ${ }^{1}$ Fabio De Iaco ${ }^{2}$ \\ ${ }^{1}$ Emergency Department, Ospedale Guglielmo da Saliceto, Piacenza; ${ }^{2}$ Emergency Department, Ospedale \\ Martini, Torino, Italy
}

\begin{abstract}
Pain is a frequent reason for referral to the Emergency Department (ED). Adequate management of pain is a moral and ethical imperative. If not correctly treated, acute pain can cause physical and psychological complications, and become chronic with severe consequences such as anxiety, depression, and social isolation. As consequence, emergency clinicians should treat pain as soon as possible, avoiding delays even in case of acute abdominal pain. Pain management is particularly complex in the elderly and emergency clinicians should always consider AGS Beers criteria ${ }^{\circledR}$ to avoid inappropriate medications, severe side-effects, and drug-drug interactions. Pain is also a common cause of delirium in older patients. The SARS CoV-2 infection not only can cause acute pain, but also exacerbate chronic pain, particularly in the elderly, who are at high risk to be infected. Looking at all this evidence, emergency clinicians should treat pain with different strategies according to their experience and cultural background, making the right choice for each patient. This work is a critical review of the pain management in the ED, with a particular attention on the
\end{abstract}

Correspondence: Erika Poggiali, Emergency Department, "Guglielmo da Saliceto" Hospital, Via Giuseppe Taverna 49, Piacenza, Italy. Tel.: +39.0523.303044

E-mail: poggiali.erika@gmail.com

Key words: Pain; pain management; Emergency Department; COVID19; pandemic.

Contributions: The authors contributed equally to the writing and critical review of the paper.

Conflicts of interest:. EP is a member of the editorial board of Emergency Care Journal. This work was not supported by any grant.

Availability of data and materials: All data generated or analyzed during this study are included in this published article.

Ethics approval and consent to participate: Not applicable.

Informed consent: Not applicable.

Received for publication: 10 June 2021.

Revision received: 24 September 2021.

Accepted for publication: 12 November 2021.

This work is licensed under a Creative Commons Attribution 4.0 License (by-nc 4.0).

CO Copyright: the Author(s), 2021

Licensee PAGEPress, Italy

Emergency Care Journal 2021; 17:9903

doi:10.4081/ecj.2021.9903 effects of COVID-19 in the EDs. We conducted a systematic search of the following databases: PubMed, Google Scholar, Science Direct, Medline from 2000 to 2020, using the keywords of "pain", "emergency", "COVID19", "elderly", "palliative care", "ketamine", "dexmedetomidine", and "post-traumatic stress disorder". The aim of this review is to help emergency clinicians to correctly manage pain in the ED with a new point of view regarding the pain management in COVID-19 patients.

\section{Introduction}

Pain management is a common clinical practise in the Emergency Room (ER) being pain a quite frequent cause for referral to the Emergency Department (ED). ${ }^{1}$ Even if appropriate pain therapy is a duty for all the emergency medicine physicians in Italy, as reported in the Italian Law $38 / 2010,{ }^{2}$ and it is one of the quality-of-care indicators of the $\mathrm{ED},{ }^{3}$ inadequate treatment of pain is still common in the ED. ${ }^{4}$ Pain management remains a challenge for many critical care physicians ${ }^{4}$ for different causes, as reported by Janati et al., ${ }^{5}$ i.e., the physician's fear regarding the drug's side effects, lack of knowledge about opioid dosage, lack of experience in the ED, lack of knowledge about the available pain control medications, and lack of proper supervision by the senior residents. As widely reported in literature, ${ }^{6-10}$ the education process and awareness strategies are crucial in improving the pain management process in the ED. Emergency medicine physicians should always remember that pain is a complex multidimensional condition that affects physical, mental, and social activity of the patients, reducing dramatically their quality of life. ${ }^{11,12}$ As consequence, a multidimensional approach is mandatory to avoid inappropriate pain management, which can result in dysregulation of neuroendocrine system with increased blood pressure and heart rate, and the development of coagulation disorders, pulmonary edema, and heart attack. If not correctly treated and well-managed, acute pain can become chronic, causing severe psychological consequences, such as anxiety, insomnia, depression, and social isolation, ${ }^{13}$ which are common cause for referral to the ER, and of increased costs for the health system. ${ }^{14-16}$ Chronic pain is defined as persistent or recurrent pain lasting more than 3 months or beyond the normal tissue healing, ${ }^{17}$ with an overall prevalence in the general population of around 20\%. ${ }^{18-20}$ Chronic pain is considered an important public health problem, which can affect any kind of patients and age, but it is more common in elderly patients. ${ }^{18}$ It can be a disease per se, not a symptom of other diseases. ${ }^{21}$ By definition, chronic pain cannot be treated and managed with a "conventional" therapeutic strategy focused only on the physical aspects of the pain, but a multimodal approach, which pays equal attention to the patient's psychosocial complaints, is always mandatory in the development of a long-term pain management program..$^{22}$ In Italy a law to guarantee access to palliative care and pain management has been approved on March 15 ${ }^{\text {th }}, 2020$ (Italian Law 38/2010). ${ }^{2}$ This law 
signed a crucial "cultural transformation" in the management of pain based on the dignity and autonomy of the patient in the process of care, and the development of dedicated structures for palliative care. The awareness of this law has been investigated by Del Giorno et al. demonstrating that in Italy in 2017, most of the enrolled patients with chronic pain $(61.9 \%)$ were not aware of the existence of a specific law stating their rights to receive pain management. ${ }^{18}$ These results confirm that, despite the Italian Law $38 / 2010$, there was not still adequate awareness about chronic pain in 2017 and unfortunately nowadays in Italy. Del Giorno et al. suggested a multilevel approach to solve this problem, bringing together researchers, stakeholders, practitioners, and the general population. Several studies demonstrated that patients whose primary pain is well-managed and treated in the ED have a higher overall satisfaction with hospital services. ${ }^{23-25}$ As consequence, emergency clinicians should treat pain as soon as possible, avoiding delays while waiting for laboratory or instrumental results. If we focus the attention on acute abdominal pain, pain treatment is an imperative in the ER. Management of acute abdominal pain requires both rapid initial evaluation of pain intensity and early administration of the appropriate analgesic therapy, including patients with a surgical abdomen. ${ }^{26}$ In the history of the emergency medicine, clinicians used a strategy based on withholding pain medications until a diagnosis has been formulated with the fear that analgesia should alter the physical findings and interfere with diagnosis. In 2021, the delay of acute abdominal pain treatment is no longer acceptable, and emergency medicine physicians must treat pain prior to diagnosis using the most appropriate analgesic drug, as demonstrated by several evidence-based studies. ${ }^{27-35}$ As reported in one 2007 Cochrane review by Manterola et al., ${ }^{36}$ early administration of analgesia to patients with acute abdominal pain can greatly reduce their pain and does not interfere with a diagnosis, which may even be facilitated due to the severity of physical symptoms being reduced. The same authors reported also that the use of opioid analgesics in the therapeutic diagnosis of patients with acute abdominal pain does not increase the risk of diagnosis error or the risk of error in making decisions regarding treatment. ${ }^{37}$ In this clinical scenario, a strong-acting opioid, such as morphine, is required, while weak opioids (e.g., tramadol) are not considered adequate first-line agents due to their short duration of effect. ${ }^{27,38}$ Morphine is indicated in the treatment of all types of acute abdominal pain, including acute pancreatitis ${ }^{39}$ and gallbladder diseases. ${ }^{40,41}$

When treating a patient with pain in the ED, the primary endpoint is the pain relief by the administration of different systemic analgesic agents according to the pain degree. Emergency medicine physicians should know advantages and disadvantages of choosing and using each drug, and they always should consider the clinical situation of the patients, their age, comorbidities, and medication, avoiding side effects and drug-drug interferences. ${ }^{42}$ Emergency clinicians should treat acute pain with different strategies according to their experience and cultural background, making the right choice for each patient. Non-Steroidal AntiInflammatory Drugs (NSAIDs) are commonly used to control acute low-mild degree pain. Their anti-inflammatory effect is due to inhibition of prostaglandin synthesis and thromboxanes by acting on the cyclo-oxygenase enzymes (COX-1, COX-2) ${ }^{43}$ The inhibition of COX-2 results in a strong anti-inflammatory, analgesic, and anti-pyretic effect, while the selective inhibition of COX-1 increases the risk of bleeding, gastrointestinal tract ulcers and renal dysfunction with acute renal failure. ${ }^{44}$ Ibuprofen is an effective COX-2 non-selective inhibitor that acts rapidly with a good safety profile, including the lowest risk of gastrointestinal bleeding ${ }^{45}$ and it can be used also in children. ${ }^{46}$ Ketorolac is a potent non-selective NSAIDS with a rapid analgesic effect (10 minutes) and a half-life about 5-6 hours. Due to its severe gastrointestinal toxicity with an increased risk of bleeding, in Italy, in 2015 the AIFA (Italian Medicines Agency) has forbidden the use of ketorolac combined with other NSAIDs, ${ }^{47}$ and later, in 2017, it has limited the use of ketorolac for the management of moderate-severe post-operative pain (i.v. for maximum two days, per os for maximum five days) and renal colic. ${ }^{48}$

Paracetamol is considered as NSAID for its analgesic effect even if its mechanism of action is not still completely clear. ${ }^{49}$ Paracetamol is the safest, cheapest, and easy to access drug. It can be used as "opioid-sparing drug" to optimize analgesia and minimize adverse effects, even in the perioperative pain management in children. ${ }^{50}$ Several studies have reported that multimodal regimens of NSAIDS, paracetamol and opioids in appropriate doses, can significantly improve pain scores and reduce narcotic requirements and drug-related side-effects. ${ }^{51-53}$ Moderate to severe pain usually requires opioid agents: morphine is the most common opioid used in the ED, while fentanyl is mainly used for procedural sedation due to its short half-life. ${ }^{54}$ EMONO (Equimolar Mixture Of Nitrous Oxide and Oxygen) is a safe gas, easy to use, with quick reversibility, ${ }^{55}$ that can be used in painful procedures in the ED, including wound cleaning, burns, sutures, orthopedic procedures, and placement of urinary catheter. EMONO is well-tolerated and a potent analgesic also in children. ${ }^{56,57}$ It generally causes effective and transient analgesia without altering consciousness and cognition. Side effects are generally mild and self-limiting, including nausea, dysphoria, vertigo, and headedness. ${ }^{58}$

Based on the observation that the global demography is changed in the last two decades resulting in an increased number of older people presenting to EDs with greater urgency or with the need to be admitted to hospital, ${ }^{59}$ emergency clinicians should remember that older people's management can be extraordinarily complex in the ER, and it requires specialist skills and resources ${ }^{60,61}$ All the physicians should always consider AGS Beers criteria ${ }^{\circledR}$ when they approach the elderly to avoid inappropriate medications, severe side-effects, and drug-drug interactions. ${ }^{62,63}$ Older people can be admitted to the ER for several reasons, including common diseases which are more common with advanced age, i.e. hypertension, diabetes mellitus, chronic heart diseases, dementia, and cerebrovascular diseases, ${ }^{64}$ but also acute illnesses that require a faster hospitalization or a longer lengths of stay. ${ }^{60}$ Since their admission in the ER, the emergency physician should be able to clearly identify older patients with frailty at highest risk of poor outcomes and who most likely can benefit from further specialist multidisciplinary interventions. ${ }^{65}$ As reported by Van Oppen et al., ${ }^{66}$ older people wish to have prompt waiting times, efficient care, clear communication, and comfortable environments. They have expectations for holistic care and feel a sense of vulnerability in the ER. Emergency clinicians should always offer adequate assistance to the elderly trying to adapt the principles of geriatric medicine in the $\mathrm{ER}$, and to involve in the discussion around the patients' need their caregivers, who are a crucial supportive care not only at home, but also in the ER. ${ }^{61}$ With the 2019 updates of AGS Beers criteria ${ }^{\circledR}$, several medications were added to the list of potentially inappropriate medications for most older patients. ${ }^{67}$ In the pain management, tramadol should be avoided for the risk of hyponatremia from syndrome of inappropriate antidiuretic hormone secretion, and opioids should be not prescribed in patients treated with benzodiazepines or gabapentinoids, because the increased risk of severe respiratory depression. If not correctly treated, pain can cause delirium in older patients. Delirium is a geriatric syndrome highly prevalent in hos- 
pitalized elderly patients, ${ }^{68}$ particularly in intensive care units ${ }^{69}$ and in patients with dementia. ${ }^{70}$ The diagnosis is clinical. According to the DMS-IV, ${ }^{71}$ delirium is a clear disturbance in attention (reduced ability to direct, focus, sustain, and shift attention) and awareness (reduced orientation whether in the environment). The most prominent symptoms are the acute onset of the inability to concentrate and changes in the state of alertness, ranging from agitation to psychomotor stupor. Clinicians must early diagnose delirium due to its high risk of mortality, increased morbidity, and severe distress for the patients. ${ }^{72}$ The acronym "VINDICATE" was created to remember the possible causes of delirium: Vascular, Infections, Nutrition, Drugs, Injury, Cardiac, Autoimmune, Tumours, and Endocrine. ${ }^{73}$ Delirium is preventable: the most common cause of delirium are drugs, especially those with anticholinergic activity (e.g., diuretics, digitalis, tramadol, benzodiazepines, morphine, codeine, third generation cephalosporins, corticosteroids, tricyclic antidepressants), ${ }^{74}$ and hospitalization. Treatment of delirium is based on non-pharmacological and pharmacological approaches, that should consider the pre-existing clinical diseases of the patient, realizing a mental planning of treatment according to the toxicity of the used drugs. ${ }^{75,76}$ Pain is a well-known cause of delirium, particularly in patients with dementia admitted to hospital; ${ }^{77}$ as consequence, pain treatment can reduce the risk of delirium and is required to manage delirium effectively. ${ }^{78}$ In these patients an effective pain management can contribute to prevent delirium. Pain Assessment in Advanced Dementia (PAINAD scale) is a simple, valid, and reliable instrument for measurement of pain in older patients with cognitive impairment, ${ }^{79,80}$ and it should be used also in the acute setting, including the ED. ${ }^{81,82}$ According to the National Audit of Dementia Care in General Hospitals (Royal College of Psychiatrists, 2017), ${ }^{83}$ pain and delirium assessments should be routinely conducted and properly recorded for patients with dementia. When treating pain, paraverbal and not verbal communication play a central role in developing empathy for pain, ${ }^{84}$ particularly in elderly patients. Nonpharmacological techniques are easy and simple methods, that can be efficacious in reducing pain and anxiety. Empathy for pain is associated with activity neural networks ${ }^{85-87}$ and physiological responses, such as skin conductance and increased heart rate. ${ }^{88,89} \mathrm{~A}$ recent study by Goldstein et al. ${ }^{90}$ has demonstrated the positive role of touching on cardio-respiratory function and its analgesic effect via the autonomic nervous system, confirming that social interactions can modify patient's pain perception, ${ }^{91}$ reduce stress and depression. ${ }^{92}$ These findings highlight the analgesic effect of social touch and confirm the importance of social interaction between the patient and the physician or the nurse. In several studies ${ }^{93-96}$ music therapy has been demonstrated to reduce anxiety, agitation, and pain, and to have beneficial effects on heart rate, respiratory rate, and blood pressure in the preoperative setting ${ }^{97}$ and in the intensive care unit. ${ }^{98}$ A perspective randomized trial involving patients in the intensive care unit, who require Non-Invasive Ventilation (NIV), has confirmed the beneficial effects of musical intervention in reducing anxiety in critically ill patients and as consequence, to enhance acceptance and tolerance of NIV. ${ }^{99}$ All the findings confirm that the best way to treat pain is always a combined strategy based on pharmacological and not-pharmacological approach. This learning is the basis of an optimal pain management strategy for end-oflife patients in the ED. ${ }^{100}$ The scientific knowledge on family caregivers' experience of pain management in end-of-life care is poor, but the role of family caregivers of patients with cancer or in palliative care is crucial, especially for patients with advanced disease. ${ }^{101}$ The communication between the emergency clinicians and the family caregivers should be the basis for a correct family caregivers' engagement in pain management and a good quality patient's end- of-life. ${ }^{100,102}$ When possible, the family caregiver should be present in the ER and be an active part of the strategy of pain management. As reported by Smith et al., ${ }^{103}$ emergency clinicians can experience discomfort and distress in treating patients with palliative care needs and find difficult to manage these patients in the ER because of the chaotic environment, the long wait times, and the inability to provide an optimal palliative care in conflict with the wishes of the patients and their family. Eligible patients with signs of an end-oflife trajectory with limited prognoses ${ }^{104,105}$ should be referred to hospice by the emergency clinicians, discussing hospice as a care option with the patient and the family, and working in concert with palliative medicine specialists. ${ }^{106}$

\section{The COVID-19 era}

The Coronavirus Disease 2019 (COVID-19) pandemic has hardly hit both the global medical community and the worldwide population. Northern Italy has been one of the most seriously affected country and the second, after China, to face such an unexpected pandemic. ${ }^{107}$ The spread of the virus has had a deep impact on the Italian healthcare system with the need of a prompt and deep structural and environmental reorganization of the EDs to avoid the collapse of the entire health system. ${ }^{108-112}$ As consequence, COVID-19 has dramatically and rapidly changed the working routine in the EDs and in all the hospitals with the postponing or cancellation of all elective surgical procedures, outpatient procedures and patient visits, including pain management services.

\section{COVID-19 related acute pain}

Considering the overcrowding of the Italian EDs in the so called "phase 1 of the Italian epidemic," the COVID-19 pandemic has forced the emergency medicine to use all the resources available in the fight against the viral infection and its catastrophic consequences. According to the WHO statistics, the COVID-19 case fatality rate in Italy was considerably higher than in China. ${ }^{113}$ COVID-19 is characterized by respiratory symptoms at different degree. Mild infections usually improve within few days, but COVID-19 can cause severe pneumonia with acute respiratory distress syndrome, multiple organ failure and death. As most of the viral infections, pain is quite common also in COVID-19 infected patients, who can differently complain myalgias, arthralgias, abdominal pain and headache. ${ }^{114}$ As reported in two recent reviews by Widyadharma et al. ${ }^{115}$ and Alonso-Matielo et al., ${ }^{116}$ muscle pain or myalgia is one of the most frequent symptoms among COVID19 infected patients, while neuropathic pain is rarely reported, do not respond well to different therapies, and can be associated with psychiatric disorders, e.g., depression, which can significantly decrease the patient's quality of life. ${ }^{117}$ COVID-19 patients can be admitted to the ER for acute abdominal pain, ${ }^{118}$ or complaining gastrointestinal symptoms, such as vomiting and diarrhea. ${ }^{119,120}$ Headache is a COVID-19 central neurological manifestation reported up to $90.5 \%$ of infected patients, ${ }^{121,122}$ which can be associated with fever, anosmia, arthralgia, cough, light headedness, and myalgia ${ }^{122}$ with a mechanism still unknown, but probably due to the release and increase of pro-inflammatory cytokines, the injury to endothelial vessels, and the macrophage and glial activation. ${ }^{123,124}$ COVID-19 has been demonstrated to worsen also chronic pain with several mechanisms, including exacerbation of preexisting pain, physical or mental complaints, such as stress, anxiety, and depression. ${ }^{125,126}$ 


\section{The chronic pain patients}

In this dramatic context, the care of chronic pain patients has been significantly impacted with the need to formulate new practise recommendations to inform and help physicians, based on a biopsychosocial model of pain management. ${ }^{127,128}$ As reported in literature, chronic pain patients have higher prevalence of anxiety, depression, catastrophising and suicidal ideation, ${ }^{129-132}$ and are also at increased risk of COVID-19 due to multiple factors, including comorbidities, old age, and immune suppression. ${ }^{133,134}$ Based on this observation, telehealth and telemedicine with multidisciplinary interactions have been recommended as a safe and effective way to provide medical services and patient education during COVID-19 pandemic. In particular, physicians have been recommended to use telemedicine to evaluate the patient, triage the urgency, and make suitable arrangements for treatment with the main aim to minimise delay and prevent unnecessary visits.

\section{The elderly patients}

Considering elderly patients who are generally affected by chronic pain and at high risk to be infected by SARS CoV-2, ${ }^{128,135}$ COVID-19 can significantly impair their quality of life and exacerbate personal disabilities with an increased need of care and underestimated sequelae.

\section{How to treat pain in COVID-19 patients}

Adequate analgesia and pain relief is mandatory for all COVID-19 patients. NSAIDs should be avoided to manage fever and pain in COVID-19 patients because evidence suggest that NSAIDs can increase complications from simple respiratory infections or delay recovery from infection based on the assumption that NSAIDs could increase the levels of Angiotensin Converting Enzyme (ACE), involved in the pathogenesis of COVID-19, ${ }^{136,137}$ particularly ibuprofen. ${ }^{138}$ Subsequent observations refuted this assertion. ${ }^{139-141}$ When admitted to ICU, COVID-19 patients can develop pain not only for the viral infection, but also for the discomfort associated with ICU treatment, intermittent procedural pain, and chronic pain present before admission to the ICU. ${ }^{142}$ If not correctly treated, the combination of pain, prone positioning during mechanical ventilation or extracorporeal membrane oxygenation may trigger delirium and cause peripheral neuropathies, especially when sedation and neuromuscular blocking agents are used. ${ }^{128}$ In the ED prone positioning during Non-Invasive Ventilation (NIV) has been used during COVID-19 pandemic. ${ }^{143,144}$ A continuous infusion of morphine has been used to increase the compliance to NIV (C-PAP in helmet) and reduce the anxiety linked to the situation, which improved the patient's compliance. ${ }^{145}$ Ketamine has been suggested by several authors as sedative in mechanically ventilated COVID-19 patients ${ }^{146}$ not only for its well-known potent analgesic and sedative effects, but also for its anti-inflammatory role, which could be central in the hyperinflammatory response observed in COVID-19 patients. ${ }^{147-149}$ In a case report by Stockton and Kyle-Sidell, ${ }^{150}$ dexmedetomidine infusion has been used in a COVID-19 patient with severe hypoxemia treated with High Flow Nasal Cannula (HFNC) with good results in term of oxygenation ${ }^{151}$ and psychological effects, without the development of severe side-effects. The authors suggest that the pharmacologic properties of dexmedetomidine may help decrease the need for mechanical ventilation in COVID-19 patients and as consequence, patients' mortality. Czepiel et al. ${ }^{152}$ reported three cases of COVID-19 critically ill patients hospitalized in surge ICUs, who all developed life-threatening hyperpyrexia while being treated with dexmedetomidine for sedation. The authors postulated that the use of high-dose dexmedetomidine (above $1.5 \mu \mathrm{g} / \mathrm{kg} / \mathrm{hr}$ ) in a hyperinflammatory state, as COVID-19, can increase the risk of developing hyperpyrexia probably due to the central effects of dexmedetomidine, which can alter hypothalamic temperature regulation through disturbances in neurotransmitter expression and metabolism, and they also recommend using a dose of $0.2-0.7$ $\mu \mathrm{g} / \mathrm{kg} / \mathrm{hr}$ in COVID-19 patients.

\section{The palliative care in end-of-life COVID-19 patients}

Palliative sedation in COVID-19 critically ill patients has been a very debated issue during the phase 1 of the pandemic, when the primary endpoint in the EDs and ICUs was the correct distribution of the resources with the main aim to avoid under- and over-treatments. Palliative sedation does not mean euthanasia, but it is the right to die without suffering with a dignified death, even in a so dramatic context as COVID-19 pandemic. ${ }^{153}$ All the emergency clinicians have deeply felt the responsibility of saving many lives as possible, but also the weight of their choices in such a dramatic emergency, particularly for elderly and vulnerable patients. ${ }^{154}$ In this difficult situation, emergency clinicians should give best possibilities to those patients who have the highest probability to benefit from intensive care. Alleviation of suffering in critically ill COVID-19 patients is an ethical imperative and a medical duty, and palliative care is the response. ${ }^{155,156}$ As reported by Borasio et $a l .,,^{157}$ all dying COVID-19 patients should have access to palliative care, and if possible, emergency clinicians should share every decision-making process with intensivists, avoiding a single person decision, and in presence of refractory pain or worsening of patient's clinical condition, they should share with the patient's family the decision to start continuous palliative sedation based on morphine for pain and dyspnea, midazolam for agitation, haloperidol for delirium, and scopolamine for secretions according to the Italian Law 219/2017. ${ }^{108}$

\section{Conclusions}

Despite the large number of published manuscripts, pain management is complex and sometimes a challenge in the ED. Emergency clinicians should never underestimate pain and always consider a tailored approach for each patient, particularly COVID19 patients. The long-term consequences of COVID-19 are still unknown and should be investigated on different levels, i.e., medical and psychological. The future health policies must develop strategies not only to avoid other pandemics, but also and above to encourage immediate and targeted treatment, including palliative care and chronic pain, to reduce serious consequences for the patients and the national health system with a great attention for the EDs and the healthcare workers.

\section{References}

1. Cordell WH, Keene KK, Giles BK, et al. The high prevalence of pain in emergency medical care. Am J Emerg Med 2002;20:165-9.

2. Legge 22 dicembre 2017, n. 219. Norme in materia di consenso informato e di disposizioni anticipate di trattamento. (18G00006). GU Serie Generale n.12 del 16-01-2018. Available from: https://www.gazzettaufficiale.it/eli/ id/2018/1/16/18G00006/sg

3. Stang AS, Hartling L, Fera C, et al. Quality indicators for the assessment and management of pain in the emergency depart- 
ment: a systematic review. Pain Res Manag 2014;19:e179-90.

4. Rupp T, Delaney KA. Inadequate analgesia in emergency medicine. Ann Emerg Med 2004;43:494-503.

5. Janati M, Kariman H, Memary E, et al. Educational intervention effect on pain management quality in emergency department; a clinical audit. Adv J Emerg Med 2018;2:e16.

6. Schreiber JA, Cantrell D, Moe KA, , et al. Improving knowledge, assessment, and attitudes related to pain management: evaluation of an intervention. Pain Manag Nurs 2014;15:47481.

7. Bayuo J, Munn Z, Campbell J. Assessment and management of burn pain at the Komfo Anokye Teaching Hospital: a best practice implementation project. JBI Database System Rev Implement Rep 2017; 15:2398-418.

8. Sampson FC, Goodacre SW, O'Cathain A. Interventions to improve the management of pain in emergency departments: systematic review and narrative synthesis. Emerg Med J 2014;31:e9-e18.

9. Kasasbeh MAM, McCabe C, Payne S. Action learning: an effective way to improve cancer-related pain management. J Clin Nurs 2017;26:3430-41.

10. Ridderikhof ML, Schyns FJ, Schep NW, et al. Emergency department pain management in adult patients with traumatic injuries before and after implementation of a nurse initiated pain treatment protocol utilizing fentanyl for severe pain. $\mathrm{J}$ Emerg Med 2017;52:417-25.

11. Salvetti MdG, Pimenta CAdM, Braga PE, Corrêa CF. Disability related to chronic low back pain: prevalence and associated factors. Rev Esc Enferm USP 2012;46:16-23.

12. Askew RL, Cook KF, Revicki DA, et al. Evidence from diverse clinical populations supported clinical validity of PROMIS pain interference and pain behavior. J Clin Epidemiol 2016;73:103-11.

13. Goesling J, Clauw DJ, Hassett AL. Pain and depression: an integrative review of neurobiological and psychological factors. Curr Psychiatry Rep 2013;15:421.

14. Langley P, Muller-Schwefe G, Nicolau A, et al. The societal impact of pain in the European Union: health-related quality of life and healthcare resource utilization. J Med Econ 2010;13:571e81.

15. Gaskin DJ, Richard P. The economic costs of pain in the United States. J Pain 2012;13:715-24.

16. Andersson V, Bergman S, Henoch I, et al. Pain and pain management in hospitalized patients before and after an intervention. Scand J Pain 2017;15:22-9.

17. Merskey HE. Classification of chronic pain: descriptions of chronic pain syndromes and definitions of pain terms. Pain Suppl 1986;3:S1-226.

18. Del Giorno R, Frumento P, Varrassi G, et al. Assessment of chronic pain and access to pain therapy: a cross-sectional population-based study. J Pain Res 2017;10:2577e84.

19. Fatoye F, Gebrye T, Odeyemi I. Real-world incidence and prevalence of low back pain using routinely collected data. Rheumatol Int 2019;39:619e26.

20. Latina R, De Marinis MG, Giordano F, et al. Epidemiology of chronic pain in the Latium Region, Italy: a cross-sectional study on the clinical characteristics of patients attending pain clinics. Pain Manag Nurs 2019;20:373e81.

21. Niv D, Devor M. Chronic pain as a disease in its own right. Pain Pract 2004;4:179-81.

22. Hylands-White N, Duarte RV, Raphael JH. An overview of treatment approaches for chronic pain management. Rheumatol Int 2017;37:29e42.
23. Todd KH, Ducharme J, Choiniere M, et al. Pain in the emergency department: results of the pain and emergency medicine initiative (PEMI) multicenter study. J Pain 2007;8:460-6.

24. Gordon DB, Pellino TA, Miaskowski C, et al. A 10-year review of quality improvement monitoring in pain management: recommendations for standardized outcome measures. Pain Manag Nurs 2002;3:116-30.

25. Todd KH, Sloan EP, Chen C, et al. Survey of pain etiology, management practices and patient satisfaction in two urban emergency departments. CJEM 2002;4:252-6.

26. Natesan S, Lee J, Volkamer H, Thoureen T. Evidence-Based Medicine Approach to Abdominal Pain. Emerg Med Clin North Am 2016;34:165-90.

27. Ranji SR, Goldman LE, Simel DL, Shojania KG. Do opiates affect the clinical evaluation of patients with acute abdominal pain? JAMA 2006;296:1764-74.

28. Attard AR, Corlett MJ, Kidner NJ, et al. Safety of early pain relief for acute abdominal pain. BMJ 1992;305:554-6.

29. Pace S, Burke TF. Intravenous morphine for early pain relief in patients with acute abdominal pain. Acad Emerg Med 1996;3:1086-92.

30. LoVecchio F, Oster N, Sturmann K, et al. The use of analgesics in patients with acute abdominal pain. J Emerg Med 1997; 15:775-9.

31. Vermeulen B, Morabia A, Unger PF, et al. Acute appendicitis: Influence of early pain relief on the accuracy of clinical and US findings in the decision to operate - A randomized trial. Radiology 1999;210:639-43.

32. Mahadevan M, Graff L. Prospective randomized study of analgesic use for ED patients with right lower quadrant abdominal pain. Am J Emerg Med 2000;18:753-6.

33. Thomas SH, Silen W, Cheema F, et al. Effects of morphine analgesia on diagnostic accuracy in Emergency Department patients with abdominal pain: A prospective, randomized trial. J Am Coll Surg 2003;196:18-31.

34. Amoli HA, Golozar A, Keshavarzi S, et al. Morphine analgesia in patients with acute appendicitis: A randomised doubleblind clinical trial. Emerg Med J 2008;25:586-9.

35. Gallagher EJ, Esses D, Lee C, et al. Randomized clinical trial of morphine in acute abdominal pain. Ann Emerg Med 2006;48:150-60.

36. Manterola C, Astudillo P, Losada H, et al. Analgesia in patients with acute abdominal pain. Cochrane Database Syst Rev 2007;3:CD005660.

37. Manterola C, Vial M, Moraga J, Astudillo P. Analgesia in patients with acute abdominal pain. Cochrane Database Syst Rev 2011;1:CD005660.

38. Falch C, Vicente D, Häberle H, et al. Treatment of acute abdominal pain in the emergency room: a systematic review of the literature. Eur J Pain 2014;18:902-13.

39. Stigliano S, Sternby H, de Madaria E, et al. Early management of acute pancreatitis: A review of the best evidence. Dig Liver Dis 2017;49:585-94.

40. Abdolrazaghnejad A, Banaie M, Tavakoli N, et al. Pain management in the emergency department: a review article on options and methods. Adv J Emerg Med 2018;2:e45.

41. Thompson DR. Narcotic analgesic effects on the sphincter of Oddi: a review of the data and therapeutic implications in treating pancreatitis. Am J Gastroenterol 2001;96:1266-72.

42. Langford RM. Pain management today - what have we learned? Clin Rheumatol 2006;25:S2-8.

43. Ricciotti E, FitzGerald GA. Prostaglandins and Inflammation. 
Arterioscler Thromb Vasc Biol 2011;31:986-1000.

44. Süleyman H, Demircan B, Karagöz Y. Anti-inflammatory and side effects of cyclooxygenase inhibitors. Pharmacol Rep 2007;59:247-58.

45. Moore AR, Derry S, Straube S, et al. Faster, higher, stronger? Evidence for formulation and efficacy for ibuprofen in acute pain. Pain 2014;155:14-21.

46. Barbagallo M, Sacerdote P. Ibuprofen in the treatment of children's inflammatory pain: a clinical and pharmacological overview. Minerva Pediatr 2019;71:82-99.

47. Agenzia Italiana del Framaco (AIFA). Nota Informativa Importante su ketorolac trometamina (13/04/2015). AIFA, 2015. Available from: https://www.aifa.gov.it/web/guest//nota-informativa-importante-su-ketorolac-trometamina-1304-2015-

48. AIFA. Ketorolac. Available from: https://farmaci.agenziafarmaco.gov.it/aifa/servlet/PdfDownloadServlet?pdfFileName=f ooter 000898037850 RCP.pdf\&sys $=$ m0b113

49. Hyllested M, Jones S, Pedersen JL, Kehlet H. Comparative effect of paracetamol, NSAIDs or their combination in postoperative pain management: a qualitative review. Br J Anaesth 2002;88:199-214.

50. Wong I, St John-Green C, Walker SM. Opioid-sparing effects of perioperative paracetamol and nonsteroidal anti-inflammatory drugs (NSAIDs) in children. Paediatr Anaesth 2013;23:475-95.

51. Tan M, Law LS, Gan TJ. Optimizing pain management to facilitate Enhanced Recovery after Surgery pathways. Can J Anesth 2015;62:203-18.

52. Dunn LK, Durieux ME, Nemergut EC. Non-opioid analgesics: Novel approaches to perioperative analgesia for major spine surgery. Best Pract Res Clin Anaesthesiol 2016;30:7989.

53. Gelman D, Gelmanas A, Urbanaite D, et al. Role of multimodal analgesia in the evolving enhanced recovery after surgery pathways. Medicina (Kaunas) 2018;54:20.

54. Alford DP, Compton P, Samet JH. Acute pain management for patients receiving maintenance methadone or buprenorphine therapy. Ann Intern Med 2006;144:127-34.

55. Annequin D, Carbajal R, Chauvin P, et al. Fixed 50\% nitrous oxide oxygen mixture for painful procedures: A French survey. Pediatrics 2000;105:E47.

56. Reinoso-Barbero F, Pascual-Pascual SI, de Lucas R, et al. Equimolar nitrous oxide/oxygen versus placebo for procedural pain in children: a randomized trial. Pediatrics 2011;127:e1464-70.

57. Goldman R. Equimolar nitrous oxide/oxygen is suitable for pain control with minor pediatric procedures. J Pediatr 2011;159:874.

58. Gall O, Annequin D, Benoit G, et al. Adverse events of premixed nitrous oxide and oxygen for procedural sedation in children. Lancet 2001;358:1514-5.

59. Roberts DC, McKay MP, Shaffer A. Increasing rates of emergency department visits for elderly patients in the United States, 1993-2003. Ann Emerg Med 2008;51:769-774.

60. Aminzadeh F, Dalziel WB. Older adults in the emergency department: a systematic review of patterns of use, adverse outcomes, and effectiveness of interventions. Ann Emerg Med 2002;39:238-47.

61. Samara N, Chevalley T, Samaras D, Gold G. Older patients in the emergency department: a review. Ann Emerg Med 2010;56:261-9.

62. Charles CV, Eaton A. Highlights From the 2019 AGS Beers
Criteria ${ }^{\circledR}$ Updates. Sr Care Pharm. 2020;35:68-74.

63. DeRhodes KH. The dangers of ignoring the beers criteria-the prescribing cascade. JAMA Intern Med 2019;179:863-864.

64. Barnett K, Mercer S, Norbury M, et al. The epidemiology of multimorbidity in a large cross-sectional dataset: implications for health care, research and medical education. Lancet 2012;380:37-43.

65. Ellis G, Marshall T, Ritchie C. Comprehensive geriatric assessment in the emergency department. Clin Interv Aging 2014;9:2033-43.

66. van Oppen JD, Keillor L, Mitchell Á, et al. What older people want from emergency care: a systematic review. Emerg Med J 2019;36:754-61.

67. By the 2019 American Geriatrics Society Beers Criteria ${ }^{\circledR}$ Update Expert Panel. American Geriatrics Society 2019 Updated AGS Beers Criteria ${ }^{\circledR}$ for Potentially Inappropriate Medication Use in Older Adults. J Am Geriatr Soc 2019;67:674-94.

68. Inouye SK, Westendorp RG, Saczynski JS. Delirium in elderly people. Lancet 2014;383:911-22.

69. Pisani MA, Murphy TE, Van Ness PH. Characteristics associated with delirium in older patients in a medical intensive care unit. Arch Intern Med 2007;167:1629-34.

70. Goldberg SE, Gladman JR, Bradshaw LE, et al. The diagnosis, prevalence and outcome of delirium in a cohort of older people with mental health problems on general hospital wards. Int J Geriatr Psychiatry 2014;29:32-40.

71. European Delirium Association; American Delirium Society. The DSM-5 criteria, level of arousal and delirium diagnosis: Inclusiveness is safer. BMC Med 2014;12:141.

72. Young J, Inouye SK. Delirium in older people. BMJ 2007;334:842-6.

73. Agnoletti V, Ansaloni L, Catena F, et al. Postoperative Delirium after elective and emergency surgery: analysis and checking of risk factors. A study protocol. BMC Surg 2005;5:12.

74. Clegg A, Young JB. Which medications to avoid in people at risk of delirium: A systematic review. Age Ageing 2011;40:23-9.

75. Lauretani F, Bellelli G, Pelà G, et al. Treatment of delirium in older persons: what we should not do! Int J Mol Sci 2020;21:2397.

76. Devlin JW, Skrobik Y, Gélinas C, et al. Clinical practice guidelines for the prevention and management of pain, agitation/sedation, delirium, immobility, and sleep disruption in adult patients in the ICU. Crit Care Med 2018;46:e825-73.

77. Feast AR, White N, Lord K, et al. Pain and delirium in people with dementia in the acute general hospital setting. Age Ageing 2018;47:841-6.

78. Schreier AM. Nursing care, delirium, and pain management for the hospitalized older adult. Pain Manag Nurs 2010;11:177-85.

79. Warden V, Hurley AC, Volicer L. Development and psychometric evaluation of the Pain Assessment in Advanced Dementia (PAINAD) scale. J Am Med Dir Assoc 2003;4:9-15.

80. Goldberg R. Calculated Decisions: Pain assessment in advanced dementia (PAINAD) scale. Emerg Med Pract 2019;21:CD1-CD2.

81. Fry M, Elliott R. Pragmatic evaluation of an observational pain assessment scale in the emergency department: The Pain Assessment in Advanced Dementia (PAINAD) scale. Australas Emerg Care 2018;21:131-6.

82. Fry M, Arendts G, Chenoweth L. Emergency nurses' evalua- 
tion of observational pain assessment tools for older people with cognitive impairment. J Clin Nurs 2017;26:1281-90.

83. Royal College of Psychiatrists. National Audit of Dementia Care in General Hospitals 2016-2017: Third round of audit report. London: Royal College of Psychiatrists, 2017.

84. Singer T, Seymour B, O'Doherty J, et al. Empathy for pain involves the affective but not sensory components of pain. Science 2004;303:1157-62.

85. Jackson PL, Brunet E, Meltzoff AN, Decety J. Empathy examined through the neural mechanisms involved in imagining how I feel versus how you feel pain. Neuropsychologia 2006;44:752-61.

86. Lamm C, Decety J, Singer T. Meta-analytic evidence for common and distinct neural networks associated with directly experienced pain and empathy for pain. NeuroImage 2011;54:2492502.

87. Peled-Avron L, Goldstein P, Yellinek S, et al. Empathy during consoling touch is modulated by mu-rhythm: An EEG study. Neuropsychologia 2018;116:68-74.

88. Block AR. Investigation of the response of the spouse to chronic pain behavior. Psychosom Med 1981;43:415-22.

89. Lamm C, Porges EC, Cacioppo JT, Decety, J. Perspective taking is associated with specific facial responses during empathy for pain. Brain Res 2008;1227:153-61.

90. Goldstein P, Weissman-Fogel I, Shamay-Tsoory SG. The role of touch in regulating inter-partner physiological coupling during empathy for pain. Sci Rep 2017;7:3252.

91. Goldstein P, Shamay-Tsoory SG, Yellinek S, Weissman-Fogel I. Empathy predicts an experimental pain reduction during touch. J Pain 2016;17:1049-57.

92. Holt-Lunstad J, Birmingham W, Light KC. The influence of depressive symptomatology and perceived stress on plasma and salivary oxytocin before, during and after a support enhancement intervention. Psychoneuroendocrinology 2011;36:124956.

93. Dijkstra BM, Gamel C, van der Bijl JJ, et al. The effects of music on physiological responses and sedation scores in sedated, mechanically ventilated patients. J Clin Nurs 2010;19:1030-9.

94. Chlan LL, Weinert CR, Heiderscheit A, et al. Effects of patientdirected music intervention on anxiety and sedative exposure in critically ill patients receiving mechanical ventilatory support: a randomized clinical trial. JAMA 2013;309:2335-44.

95. Han L, Li JP, Sit JW, et al. Effects of music intervention on physiological stress response and anxiety level of mechanically ventilated patients in China: a randomised controlled trial. J Clin Nurs 2010;19:978-87.

96. Jaber S, Bahloul H, Guetin S, et al. Effects of music therapy in intensive care unit without sedation in weaning patients versus non-ventilated patients. Ann Fr Anesth Reanim 2007;26:30-8.

97. Hole J, Hirsch M, Ball E, Meads C. Music as an aid for postoperative recovery in adults: a systematic review and meta-analysis. Lancet 2015;386:1659-71.

98. Bradt J, Dileo C. Music interventions for mechanically ventilated patients. In: The Cochrane Collaboration, editor. Cochrane Database Syst Rev 2014;2014:CD006902.

99. Messika J, Hajage D, Panneckoucke N, et al. Effect of a musical intervention on tolerance and efficacy of non-invasive ventilation in the ICU: study protocol for a randomized controlled trial (MUSique pour l'Insuffisance Respiratoire Aigue - MusIRA). Trials. 2016;17:450.

100. Gisondi MA. A case for education in palliative and end-of-life care in emergency medicine. Acad Emerg Med 2009;16:181-3.
101. Ferrell BR. Family caregiving and cancer pain management. Anesth Analg 2019;129:1408-13.

102. Chi NC, Demiris G. Family caregivers' pain management in end-of-life care: a systematic review. Am J Hosp Palliat Care 2017;34:470-85.

103. Smith AK, Fisher J, Schonberg MA, et al. Am I doing the right thing? Provider perspectives on improving palliative care in the emergency department. Ann Emerg Med 2009;54:86-93.

104. Teno JM, Shu JE, Casarett D, et al. Timing of referral to hospice and quality of care: length of stay and bereaved family members' perceptions of the timing of hospice referral. J Pain Symptom Manage 2007;34:120-5.

105. Quill TE. Is length of stay on hospice a critical quality of care indicator? J Palliat Med 2007;10:290-2.

106. Lamba S, Quest TE. Hospice care and the emergency department: rules, regulations, and referrals. Ann Emerg Med 2011;57:282-90.

107. Remuzzi A, Remuzzi G. COVID-19 and Italy: what next? Lancet 2020;395:1225-8.

108. Poggiali E, Vercelli A, Mazzoni S, et al. COVID-19 pandemic, Piacenza calling. The survival strategy of an Italian emergency department. Acta Biomed 2020;91:1-3.

109. Maniscalco P, Poggiali E, Quattrini F, et al. The deep impact of novel covid-19 infection in an Orthopedics and traumatology department: The experience of the Piacenza hospital. Acta Biomed 2020;91:97-105.

110. Comelli I, Scioscioli F, Cervellin G. Impact of the covid-19 epidemic on census, organization and activity of a large urban emergency department. Acta Biomed 2020;91:45-9.

111. Turcato G, Zaboli A, Pfeifer N. The COVID-19 epidemic and reorganisation of triage, an observational study. Intern Emerg Med 2020;15:1517-24.

112. Carenzo L, Costantini E, Greco M, et al. Hospital surge capacity in a tertiary emergency referral centre during the COVID-19 outbreak in Italy. Anaesthesia 2020;75:928-34.

113. World Health Organization. Coronavirus disease 2019 (COVID-19) Situation Report - 72. Available from: https://covid19.who.int/ (last access 16th November 2021)

114. Drozdzal S, Rosik J, Lechowicz K, et al. COVID-19: pain management in patients with SARS-CoV-2 infectionmolecular mechanisms, challenges, and perspectives. Brain Sci 2020;10:465.

115. Widyadharma IPE, Sari NNSP, Pradnyaswari KE, et al. Pain as clinical manifestations of COVID-19 infection and its management in the pandemic era: a literature review. Egypt J Neurol Psychiatr Neurosurg 2020;56:121.

116. Alonso-Matielo H, da Silva Oliveira VR, de Oliveira VT, Dale CS. Pain in Covid Era. Front Physiol 2021;12:624154.

117. Guo R, Chen L, Xing C, Liu T. Pain regulation by gut microbiota: molecular mechanism and therapeutic potential. $\mathrm{Br} \mathrm{J}$ Anaesth 2019;123:637-54.

118. Zhai L, Wang W, Wu L, Tang Z. Clinical Intelligence COVID19 with abdominal symptoms and acute abdominal pain: a guide to identification for generalpractice. $\mathrm{Br} \mathrm{J}$ Gen Pract 2020;70:358-9.

119. Oba J, Carvalho WB, de Silva CA, Delgado AF. Gastrointestinal manifestations and nutritional therapy during COVID-19 pandemic: a practical guide for pediatricians. Einstein (Sao Paulo) 2020;18:eRW5774.

120. Poggiali E, Ramos PM, Bastoni D, et al. Abdominal pain: a real challenge in novel COVID-19 infection. Eur J Case Rep Intern Med 2020;7:001632.

121. Lechien JR, Chiesa-Estomba CM, Place S, et al. Clinical and 
epidemiological characteristics of 1420 European patients with mild-to-moderate coronavirus disease 2019. J Intern Med 2020;288:335-44.

122. Trigo J, García-Azorín D, Planchuelo-Gómez Á, et al. Factors associated with the presence of headache in hospitalized COVID-19 patients and impact on prognosis: a retrospective cohort study. J Headache Pain 2020;21:1-10.

123. Su S, Cui H, Wang T, et al. Pain: a potential new label of COVID-19. Brain Behav Immun 2020;87:159-60.

124. Kanberg N, Ashton NJ, Anderson LM, et al. Neurochemical evidence of astrocytic and neuronal injury commonly found in COVID-19. Neurology 2020;95:e1754-9.

125. Lei L, Huang X, Zhang S, et al. Comparison of prevalence and associated factors of anxiety and depression among peopleaffected by versus people unaffected by quarantine during the COVID-19 Epidemic in Southwestern China. Med Sci Monit 2020;26:1-12.

126. Majumdar P, Biswas A, Sahu S. COVID-19 pandemic and lockdown: cause of sleep disruption, depression, somatic pain, and increased screen exposure of office workers and students of India. Chronobiol Int 2020;37:1191-1200.

127. American Society of Regional Anesthesiology. Recommendations on chronic pain practice during the COVID19 pandemic. ASRA; 2020. Available from: https://www.asra.com/page/2903/recommendations-on-chronic-pain-practice-during-the-covid-19-pandemic

128. Shanthanna H, Strand NH, Provenzano DA, et al. Caring for patients with pain during the COVID-19 pandemic: consensus recommendations from an international expert panel. Anaesthesia 2020;75:935-44.

129. Darnall BD, Carr DB, Schatman ME. Pain psychology and the biopsychosocial model of pain treatment: ethical imperatives and social responsibility. Pain Medicine 2017;18:1413-5.

130. Lautenbacher S, Kundermann B, Krieg JC. Sleep deprivation and pain perception. Sleep Med Rev 2006;10:357-369. 24.

131. Barry DT, Pilver C, Potenza MN, Desai RA. Prevalence and psychiatric correlates of pain interference among men and women in the general population. J Psychiatr Res 2012;46:118 27.

132. Tang NK, Crane C. Suicidality in chronic pain: a review of the prevalence, risk factors and psychological links. Psychol Med 2006;36:575-86.

133. Ren K, Dubner R. Interactions between the immune and nervous systems in pain. Nature Medicine 2010;16:1267-76.

134. Marchand F, Perretti M, McMahon SB. Role of the immune system in chronic pain. Nature Rev Neurosci 2005;6:521-32.

135. Chen G, Wu D, Guo W, et al. Clinical and immunological features of severe and moderate coronavirus disease 2019. J Clin Invest 2020;130:2620-9.

136. Pergolizzi JV Jr, Varrassi G, Magnusson P, et al. COVID-19 and NSAIDS: A narrative review of knowns and unknowns. Pain Ther 2020;9:353-8

137. Russell B, Moss C, Rigg A, Van Hemelrijck M. COVID-19 and treatment with NSAIDs and corticosteroids: should we be limiting their use in the clinical setting? Ecancermedicalscience 2020;14:1023.

138. Day M. Covid-19: ibuprofen should not be used for managing symptoms, say doctors and scientists. $\mathrm{Br}$ Med J 2020;368:m1086.

139. British Medical Journal Best Practice. Coronavirus disease 2019 (COVID-19). Available from: https://bestpractice.bmj.com/info/coronavirus covid-19/

140. Food and Drug Administration. FDA advises patients on use of non-steroidal anti-inflammatory drugs (NSAIDs) for COVID19. FDA; 2020. Available from: https://www.fda.gov/drugs/drug-safety-and-availability/fdaadvises-patients-use-non-steroidal-anti-inflammatory-drugsnsaids-covid-19

141. EMA gives advice on the use of non-steroidal anti-inflammatories for COVID-19, 2020. Available from: https://www.ema.europa.eu/en/news/ema-gives-advice-usenon-steroidal-anti-inflammatories-covid-19

142. Drożdżal S, Rosik J, Lechowicz K, et al. COVID-19: Pain Management in Patients with SARS-CoV-2 InfectionMolecular Mechanisms, Challenges, and Perspectives. Brain Sci 2020;10:465.

143. Caputo ND, Strayer RJ, Levitan R. Early self-proning in awake, non-intubated patients in the emergency department: a single ED's experience during the COVID-19 pandemic. Acad Emerg Med 2020;27:375-8.

144. Coppo A, Bellani G, Winterton D, et al. Feasibility and physiological effects of prone positioning in non-intubated patients with acute respiratory failure due to COVID-19 (PRONCOVID): a prospective cohort study. Lancet Respir Med 2020;8:765-74

145. Bastoni D, Poggiali E, Vercelli A, et al. Prone positioning in patients treated with non-invasive ventilation for COVID-19 pneumonia in an Italian emergency department. Emerg Med J 2020;37:565-6.

146. Ortoleva J. Consider adjunctive ketamine in mechanically ventilated Coronavirus Disease-2019 patients. J Cardiothorac Vasc Anesth 2020;34:2580.

147. Weinbroum AA. Perspectives of ketamine use in COVID-19 Patients. J Korean Med Sci 2021;36:e28.

148. Vabretabret N, Britton GJ, Gruber C, et al. Immunology of COVID-19: current state of the science. Immunity. 2020;52(6):910-41.

149. Akinosoglou K, Gogos A, Papageorgiou C, et al. Ketamine in COVID-19 patients: Thinking out of the box. J Med Virol 2020:10.1002/jmv.26681

150. Stockton J, Kyle-Sidell C. Dexmedetomidine and worsening hypoxemia in the setting of COVID-19: A case report. Am J Emerg Med 2020;38:2247.e1-2247.e2.

151. Hasanin A, Taha K, Abdelhamid B, et al. Evaluation of the effects of dexmedetomidine infusion on oxygenation and lung mechanics in morbidly obese patients with restrictive lung disease. BMC Anesthesiol 2018;18:104.

152. Czepiel KS, Lucas AT, Whalen MJ, Mojica JE. Dexmedetomidine-associated hyperpyrexia in three critically ill patients with coronavirus disease 2019. Crit Care Explor 2020;2:e0213.

153. Buonanno P, Vargas M, Marra A, et al. End of life in the time of COVID-19 pandemic: take care of death. Acta Biomed 2020;91:e2020153.

154. Doldi M, Moscatelli A, Ravelli A, et al. Medicine and humanism in the time of COVID-19. Ethical choices. Acta Biomed 2020;91:e2020167.

155. The Lancet. Palliative care and the COVID-19 pandemic Lancet. 2020;395:1168.

156. Powell VD, Silveira MJ. What should palliative care's response be to the COVID-19 pandemic? J Pain Symptom Manage 2020;60:e1-e3.

157. Borasio GD, Gamondi C, Obrist M, Jox R, For The Covid-Task Force Of Palliative Ch. COVID-19: decision making and palliative care. Swiss Med Wkly 2020;150:w20233. 